\title{
Instituciones y gestión del desarrollo rural en la Argentina degradada: hacia la reconstrucción de la nación
}

\author{
Mabel ManZanal *
}

\begin{abstract}
The aim of this article is to show the importance that institutional issues have in the national development at the end 2001, being this year the landmark to the deepest economical and socio-political crisis in Argenti$n a$. We are interested in presenting some information about the forms of institutional management in the rural development, which can be considered as alternatives of local transformation towards social change. We explore territorial experiences searching for evidence about the social realities and agents that demonstrate the possibilities and difficulties that arise when trying to consolidate a nation from a common project and within an institutional frame. We analyse in depth the micro experiences in local development in order to identify institutional forms associated with a more equitable redistribution. We highlight the importance of basic organizations, as well as the rural population training to achieve greater and more transparent forms of participation, decision making and institutional control.
\end{abstract}

Keywords: Territory, local development, rural development, institutions, economical development.

\section{Resumen}

Se plantea la importancia de la cuestión institucional en el desarrollo nacional, enmarcado en el contexto de fines de 2001, hito que señala la más profunda crisis económica y sociopolítica de Argentina. Nuestro interés es aportar información sobre formas de gestión institucional en desarrollo rural, que pueden considerarse alternativas de transformación local con perspectiva de cambio social. Exploramos experiencias territoriales en busca de evidencias sobre realidades y actores sociales que den cuenta de las posibilidades y dificultades cuando se plantea conformar una nación desde un proyecto común y en un marco institucional. Profundizamos el análisis de experiencias micro de desarrollo local, para identificar formas institucionales asociadas con un desarrollo más equitativo. Subrayamos la importancia que tienen las organizaciones de base y la capacitación de la población rural (y de ámbitos locales) para alcanzar mayores grados y formas más transparentes de participación, decisión y control institucional.

Palabras clave: Territorio, desarrollo local, desarrollo rural, instituciones, desarrollo económico.

* Facultad de Filosofía y Letras, Universidad de Buenos Aires, CONICET. Correo-e: postmaster@manzan.ba.ar 


\section{Introducción $^{1}$}

Los valores récord que la desocupación y la pobreza alcanzaron en la Argentina en mayo de $2002^{2}$ son la expresión de una expansión sostenida de la exclusión laboral, la pobreza, el hambre y la desnutrición, pero también una demostración de la inseguridad jurídica e institucional existente en el país. El neoliberalismo se nutre de una creciente polarización y desigualdad social que para sostenerse en estas condiciones, y bajo formas representativas y 'pseudo' democráticas, requiere un estilo de gestión pública (articulada con el accionar de ciertos sectores privados) lindante entre lo ilícito y lo ilegal, pero devenido en 'legítimo' tras la máscara de la eficacia en el 'logro' de determinados fines (validadas en frases como: 'roba pero hace'). De todas formas, justificaciones 'facilistas' y formas corruptas, prebendarias, dolosas, existen desde larga data en la historia nacional, pero con el neoliberalismo se constituyeron en sistema enquistado en el poder.

José Nun (2003:2) califica la crisis institucional de la Argentina como estructural, descartando que pueda calificársela como una crisis de representatividad (coyuntural). Identifica a las crisis estructurales como aquellas en que las instituciones dejan de cumplir los fines para los que fueron creadas, y donde la población no recurre a las instituciones porque desconfía o supone que no le solucionarán su problema, o incluso se lo agravarán.

Nuestra percepción es que ahora desenmascarada la crisis socioeconómica (latente durante los años 90, pero evidenciada para la gran mayoría de la población recién a fines de 2001), existen condiciones favorables para reconstruir una Argentina que priorice la justicia social, dada la nueva conciencia social sobre nuestra real situación socioeconómica y nuestras posibilidades y limitaciones en ese contexto. Y precisamente, nuestro objetivo en este

${ }^{1}$ Este artículo es parte de una investigación dirigida por la autora y denominada "Problemática institucional y desarrollo rural", que cuenta con el apoyo financiero del Consejo Nacional de Investigaciones Científicas y Tecnológicas (CONICET), de la Universidad de Buenos Aires (UBA) y del Fondo Nacional de Ciencia y Tecnología (SEPCyT), Argentina. Fue presentado en el vII Seminario de la Red Iberoamericana de Investigadores sobre globalización y territorio (RII), 27 al 29 de noviembre de 2002, Camagüey, Cuba.

${ }^{2}$ La desocupación fue de 21.5\% (3’038,000 personas) más 13\% la subocupación (INDEC-EPH, 2002). Los pobres e indigentes eran 20.8 millones, $57.5 \%$ de la población (con 10 millones los indigentes, 27.5\%). Hacia octubre de 2002, estos indicadores mejoraron porque el desempleo logró descender a $17.8 \%$, producto de los aumentos postdevaluación de la producción. 
artículo es plantear la importancia que la cuestión institucional tiene para ese tipo de transformación nacional.

Nuestro interés es aportar información sobre formas de gestión institucional en desarrollo rural, que pueden considerarse alternativas de transformación local con perspectiva de cambio social. Exploramos experiencias territoriales (acotadas social, económica y espacialmente) buscando evidencias sobre realidades y actores sociales que den cuenta de las posibilidades y dificultades que aparecen cuando se busca conformar una nación desde un proyecto común y dentro de un marco institucional que lo viabilice.

Nuestra propuesta de investigación (que aquí sólo presentamos en sus aspectos más generales y teóricos para someter a la discusión) busca profundizar el análisis de experiencias micro de desarrollo local, con el objetivo de identificar formas institucionales asociadas a un desarrollo más equitativo en la redistribución de los recursos económicos y sociales y que, conjuntamente, puedan resultar enseñanzas para otros ámbitos.

Nuestra hipótesis de trabajo se fundamenta en la importancia que tiene el fortalecimiento de las organizaciones de base y la capacitación de la población rural (y de ámbitos locales) para alcanzar mayores grados y formas más transparentes de participación, de decisión y de control institucional (además de influenciar, también, en la propia realidad de las familias productoras, con mejoras en la calidad de vida y en los ingresos familiares).

La siguiente exposición está organizada en cuatro apartados. En el primero, enmarcamos la crisis argentina especialmente en cuanto a la dificultad o posibilidad de revertirla desde la cuestión institucional. En el segundo, desarrollamos los conceptos y las variables de la temática que nos ocupa; en el tercero, presentamos las características generales y los aspectos más relevantes que surgen de los casos de estudio. Finalmente, bosquejamos algunas conclusiones sobre las posibilidades y restricciones presentes en la gestión institucional del desarrollo rural en Argentina.

\section{La irrupción de una crisis preexistente y el marco institucional de la Argentina actual}

El quiebre institucional que se ha producido en la Argentina como resultado de la secuencia de hechos de violencia y conflicto social es el desenlace de una crónica anunciada aunque no reconocida (Manzanal, 1995: 80-81). Hoy existe una nueva oportunidad, producto de esta crisis, calificada ahora como 'terminal', para re- 
ver el rumbo del desarrollo nacional. Lamentablemente, por la fuerza de los hechos, una significativa porción de la población comprendió que el desconocimiento sistemático de las instituciones (sea a través de golpes de Estado, la desaparición de personas, el desconocimiento de los acuerdos previos, o los manejos corruptos de la cosa pública) termina erosionando la estructura de funcionamiento de la nación misma. En este sentido fueron la dictadura militar de 1976 y el gobierno democrático de Menem, con su respectiva ambición de perpetuarse en el poder, los principales impulsores de este desenlace. Sin embargo, este presente: i) es producto de hechos políticos gestados y acumulados en diferentes periodos gubernamentales de la historia nacional; ii) las políticas de ajuste macroeconómico fueron adoptadas indistintamente por gobiernos militares, radicales y justicialistas, y iii) el proceso de endeudamiento no sólo no se detuvo, sino que se aceleró, a pesar de que se privatizaron empresas y recursos nacionales rentables (petróleo, gas, transporte) para afrontar el pago de la deuda (aunque el slogan fuera "la mayor eficiencia privada"). Es decir, la crisis no aparece en el 2001, sólo se torna tangible para amplias mayorías nacionales e internacionales.

Es el modelo económico el que ha llevado a esta crisis estructural que ha afectado a las instituciones y a las estructuras productivas nacionales, y que por ello produce un daño al crecimiento, al empleo, al nivel de vida, a la confianza institucional, que no podrán revertirse en el corto plazo. En la Argentina, desde la recuperación democrática operada en 1983, los dos partidos mayoritarios se han sucedido en el ejercicio del Poder Ejecutivo. Y ambos han operado crecientemente bajo formas clientelísticas: la búsqueda de votos y apoyos económicos a cambio de dádivas, preferencias, prioridades y manejos dolosos y prebendarios en la administración de la cosa pública. Este funcionamiento fue posible porque existieron y se modelaron instituciones acordes al mismo. Y ésta fue y es una realidad en expansión, en la que están comprometidas, y siguen estándolo, organizaciones del sector público y del privado (empresarios en su mayoría de los estratos de mayor poder económico). Pero, además, este funcionamiento terminó alcanzando a la población en general, a empresarios, productores, comerciantes. El aumento, la difusión y la expansión e interacciones del accionar corrupto inhibieron, finalmente, la actividad económica como un todo, incrementando los costos de producción, de transacción, de la seguridad individual y social. 
Llegando, finalmente, a tornar no confiables a casi todas las instituciones que regulan el funcionamiento de la nación.

La incautación del dinero de los ahorristas (plazos fijos, depósitos en cuenta corriente y caja de ahorro) es la demostración más acabada de la destrucción total de una de las instituciones más creíbles hasta ese momento, como eran los contratos que los bancos celebraban con sus clientes para resguardar y garantizar la rentabilidad del dinero por ellos depositado. Del mismo modo, perdió credibilidad la jurisprudencia proveniente de una justicia desacreditada, y las normas y la legislación resultante de un Poder Legislativo totalmente cuestionado.

Entonces, ¿̇cómo 'desarmar' un modelo de corrupción institucionalizada y de hondo contenido histórico? Téngase en cuenta que, a pesar de que el país vive una crisis económica, Argentina puede plantearse el desafío de ampliar significativamente el mercado interno y proyectarse competitivamente hacia el externo. Pero un condicionamiento central es la crítica situación de su modelo institucional y político, tanto por razones éticas, culturales y de degradación creciente de valores, como por razones económicas. Ya que el propio crecimiento económico se restringe cuando las inversiones no tienen factibilidad económica o se tornan muy volátiles en medio de la incertidumbre y corrupción que asola al país.

¿Y cómo se hace para cambiar el rumbo transitado históricamente e institucionalizado durante décadas?, ¿cómo se interpone una contención a los negociados entre el sector público y el privado y, en general, a todo accionar burocrático, fraudulento y corrupto?, ¿cómo se alcanza un funcionamiento transparente, solidario y democrático que neutralice, denuncie y termine pulverizando los modelos prebendarios y corruptos, el funcionamiento clientelístico y de compensación social, operado tanto en ámbitos nacionales, provinciales como locales, públicos como privados?

Es evidentemente necesario terminar con la impunidad. Y para ello no hay otra forma que institucionalizar un activo control y seguimiento social, donde la aplicación de premios y castigos asegure avanzar paulatinamente hacia normas y prácticas, formales e informales, que se apliquen con continuidad, regularidad y permanencia, y en forma universal y generalizada. Para acabar con la impunidad hay que aumentar los controles y en ello la participación y gestión de la población involucrada cumple un rol imprescindible. 
Pero, además, la mayor participación ciudadana conduce a la construcción de otro polo de poder político, también necesario para incorporar a las mayorías, hoy excluidas del mercado de trabajo y de una vida digna, en la gestión y control del Estado (sea nacional, provincial o local), como veremos en el siguiente apartado.

\section{El marco interpretativo}

El modelo neoliberal de los últimos 25 años agudizó el desprestigio y la arbitrariedad en el funcionamiento de las instituciones nacionales. ${ }^{3}$

$\mathrm{Al}$ respecto, cabe preguntarse: ¿cómo se retoma el control de la esfera pública?, ¿es necesario cambiar el gobierno o cambiar el Estado?, ¿cómo se construye un nuevo Estado que no reincida en la saga de soborno, clientelismo y corrupción?

Cualquier gobierno que quiera aplicar un proyecto nacional alternativo sólo podrá hacerlo si antes cuenta con el apoyo mayoritario de la población, consciente del cambio que se les exige y que la involucrará. Es decir, se necesita contraponer un polo de poder popular. Esto sólo se construye a partir de la participación cotidiana y regular de la población en las diferentes formas de gestión, control y seguimiento del accionar público y privado; y pese a que éste es un requisito necesario, no es suficiente. En lo que hace, en particular, a la participación, depende de la forma y tipo que la misma asuma. Aquí nos estamos refiriendo a: i) aquella participación que interviene en las decisiones públicas; ii) que se ejerce controlando 'la eficiencia, la transparencia y la efectividad' de las acciones públicas y privadas, y iii) cuyos objetivos son mejorar la distribución del producto (nacional, provincial o lo-

${ }^{3}$ Consecuencias institucionales resultantes del modelo neoliberal aparecen, incluso, en los Estados Unidos, donde escándalos económicos pusieron en cuestión la conducta corporativa empresaria y la gobernabilidad. Benjamin Barber (Clarín, 1-8-02) refiriéndose a Estados Unidos afirma que la corrupción en ese país es resultado del: "[...] fracaso de los instrumentos de la democracia, que se vieron debilitados por tres décadas de fundamentalismo de mercado, de ideología de la privatización y de hostilidad hacia el Estado [...] nos volvimos demasiado tímidos como ciudadanos, aceptando la desregulación y la privatización (líneas aéreas, estudios contables, bancos, consorcios de medios, y la lista sigue) y una tiranía creciente del dinero sobre la política [...] Estas políticas pueden atribuirse directamente a ese soberbio desdén por el ámbito público [...] los capitalistas prófugos, los ignorantes de la ecología, los contadores irresponsables, los contrabandistas amorales de drogas y los terroristas antimodernos prosperan porque hemos reducido el poder de la esfera pública. Al privatizar las funciones de gobierno y negarnos a contribuir a crear instituciones democráticas de gobernabilidad global, Estados Unidos renunció a su autoridad para controlar estas fuerzas.” 
cal) en favor de las mayorías nacionales, crecientemente postergadas.

El camino hacia esta reconstrucción demanda consecutivamente: i) i participación popular (pero no cualquier forma de participación); ii) transformación institucional del Estado inducido por la creciente participación popular (conformando un Estado diferente al que hoy reconocemos como tal), y iii) transformación de las instituciones que regulan el accionar privado (empujada por las dos anteriores).

En otras palabras, para que las propuestas vinculadas con el desarrollo tengan viabilidad (estén centradas en una economía solidaria y popular ${ }^{4}$ o en el rol del Estado impulsando el crecimiento del mercado interno) deberán aplicarse a partir de nuevas instituciones, nuevos modelos de gestión, que desarmen las prácticas económicas y políticas envilecidas, prebendarias y corruptas. Esto implica: i) hacer cumplir las normativas y leyes; ii) darles regularidad, certidumbre y transparencia, y iii) valorizar la experiencia, el conocimiento idóneo, el aprendizaje y las prácticas burocráticas basadas en la ética, la austeridad y la responsabilidad.

Todo esto vale tanto para las instituciones públicas como para las privadas. Pero este objetivo no puede lograrse si no es en un contexto de búsqueda de consenso y acuerdo entre las grandes mayorías para compatibilizar intereses y dirimir conflictos (a partir de la opinión de la mayoría o del dictamen del conocimiento experto -aunque sean perjudiciales para algunos-, véase Brett, 1999a: 27). Y en ese sendero de transformación institucional, de búsqueda de consenso, la participación de la población cumple un rol fundamental.

Precisamente, en lo que sigue identificaremos este marco analítico, comenzando por los principales conceptos y premisas que utilizamos.

\subsection{Las unidades de análisis}

Adoptamos la concepción de Instituciones de North:

${ }^{4}$ Coraggio (1998: 12 y ss.) identifica como sujeto de la "economía popular" a los individuos o grupos domésticos que dependen para su reproducción de la realización ininterrumpida de su fondo de trabajo. Y define como "economía popular" a: i) el conjunto de recursos que comandan dichos individuos, ii) las actividades que realizan para satisfacer sus necesidades de manera inmediata o mediata, iii) las reglas, valores y conocimientos que orientan tales actividades, y iv) los correspondientes agrupamientos, redes y relaciones -de concurrencia, regulación o cooperación, internas o externas- que instituyen a través de la organización formal o de la repetición de esas actividades. 
Instituciones son las reglas de juego en una sociedad, o más formalmente, son coacciones, restricciones o limitaciones ideadas por el hombre para conducir la interacción humana. En consecuencia, ellas estructuran los incentivos en el intercambio humano (sean políticos, sociales o económicos). El cambio institucional conforma el camino que la sociedad desarrolla a través del tiempo y, por lo tanto, es la llave para comprender el cambio histórico [traducción nuestra] (North, 1999: 3).

Y al respecto, coincidimos con Brett cuando al respecto de las funciones de las instituciones afirma:

Las instituciones son un sistema de reglas y prácticas colectivas que habilitan, y aún fuerzan, a los individuos a trabajar juntos en un proyecto común (Brett, 1999a: 47).

Y porque, precisamente, una nación es un proyecto común a todos sus ciudadanos, Brett sostiene que:

[...] la creación de un sistema judicial imparcial y accesible, tanto como la instauración del imperio de la ley antes que la arbitrariedad del poder, es crucial para la legitimidad de largo plazo y la estabilidad del Estado [cursiva y traducción nuestra] (Brett, 1999a: 28).

Por ello, cuando analizamos la naturaleza de las instituciones que regulan el accionar humano en determinada organización jurídica (sea en una nación, o en un conjunto de países unidos por integraciones regionales), nos adentramos en el conocimiento del efecto de dichas instituciones sobre el desarrollo socioeconómico respectivo. Es nuestro caso particular: enfocarse en el impacto de las instituciones sobre el desempeño económico de actividades locales ligadas al desarrollo rural.

A esta altura, quizá, debamos aclarar que las instituciones no son las organizaciones (grupos, actores o individuos con un objetivo común) que administran y aplican programas y políticas. Tampoco son los agentes que las operan (véase Ayala, 1999: 64). Es decir, distinguimos instituciones de organizaciones. Las instituciones son las normas o reglas, pero no cualquier norma o regla, sino sólo aquellas que son compartidas y conocidas y que se acepta su cumplimiento, sea voluntaria o coercitivamente (véase Ayala, 1999: 61). Por su parte, organizaciones refiere a personas que operan conjuntamente para alcanzar determinados objetivos (y éstos pueden ser consensuados o no) ya que:

[...] los individuos tienen incentivos para construir organizaciones porque esperan mayores beneficios que si se mantuvieran aislados (Ayala, 
1999: 21) [...] Las organizaciones son un fenómeno común en nuestro medio. En términos amplios, la familia, la escuela, los servicios públicos, las empresas, sindicatos, equipos deportivos, asociaciones religiosas, sociales, de entretenimiento y hasta nuestro grupo de amigos, son organizaciones. Las instituciones, en tanto restricciones diseñadas por el hombre para modelar la interacción humana, son semejantes a las organizaciones, éstas proveen de una estructura para la interacción social. Ambas surgen de la acción humana y tienen como objetivo minimizar los costos derivados del intercambio. Pero no deben confundirse, la organización es la arena en la cual los agentes realizan intercambios acotados por las instituciones existentes [cursiva nuestra] (Ayala, 1999: 282).

Es decir, las organizaciones son las estructuras donde se opera, donde se trabaja y donde se distribuyen las funciones, mientras que las instituciones son las normas, las reglas y las creencias que regulan dichas funciones y actividades. Son estas últimas, en definitiva, las que otorgan sentido, significado, a las organizaciones.

Las normas, creencias y regulaciones configuran un determinado modelo de participación de los involucrados (sean directivos o empleados o la misma sociedad civil). Según cuáles sean estas normas, se habilitará un particular modelo de participación, con diferente apertura o no hacia la sociedad local respectiva. Brett acota que los distintos teóricos acuerdan en que la:

[...] participación es un proceso por el cual la población, especialmente los sectores sociales menos favorecidos, influyen en las decisiones que los afectan (Brett, 1999b:4).

Y distingue entre una participación débil (asociada a participar para informar o para ser consultado) de una participación fuerte (que significa asociarse para las decisiones y aún ceder el control). Asimismo Brett (1999b: 5) considera que muchas organizaciones, si bien postulan una participación fuerte, en los hechos, sea por la escala o por su naturaleza jerárquica, no superan las formas de participación débil, que sólo implica la obligación de informar y consultar a beneficiarios y usuarios.

Para Brett (1999b: 5), la participación no debería ser tratada como un nuevo y revolucionario paradigma, sino como un elemento general de aproximación a la administración del desarrollo, que reconoce la necesidad de la jerarquía, la capacidad experta y la disciplina en el servicio tanto como el control "de abajo hacia arriba".

La participación que aquí nos interesa es aquella que se centra en el control y seguimiento de las acciones públicas y privadas. 
Porque ésta es la que más se vincula con el cumplimiento de los acuerdos y normas. Pero no es exclusivamente el control, nos interesa también que el resultado de dicho control se ejerza a través del ejercicio de premios y castigos a la labor controlada.

Hay otra faceta de la participación de suma importancia: aquella en la que los actores de la sociedad civil avanzan en la toma de decisiones; ellos mismos toman buena parte, o la mayor parte, de las decisiones que los involucran y que tienen que ver con sus actividades. Esta forma de participación es el paradigma de todo modelo de participación que busca la transformación de la sociedad del presente. Porque la participación paulatina y constante en las decisiones capacita a quienes la ejercen y es el motor de la transformación social. Precisamente Brett (1999b: 7) sostiene que los defensores de este tipo de participación la consideran, no exclusivamente como un método para el desarrollo, sino fundamentalmente como un nuevo paradigma para la transformación social.

Nos adherimos a esta postura, sin que ello signifique un funcionamiento anárquico y carente de dirección política (entendida la política en su sentido amplio y no restringiéndola a la acción del Estado). Lo vemos como un proceso paulatino de largo plazo, que va construyendo conciencia, aprendizaje y consenso. Consideramos que, en una primera etapa, este tipo de participación puede ser aplicada sólo a determinado rango de actividades que deberán identificarse en cada caso (dependiendo de los niveles de capacitación, herramientas y técnicas disponibles). Y que avanzar hacia niveles de mayor complejidad dependerá de los modos y avances de los procesos de capacitación, organización y de la práctica misma de participación.

Consideramos que el control y seguimiento del funcionamiento transparente y del cumplimiento regular de las normas y reglas es la primera forma de participación, que, además, es altamente formadora para alcanzar modelos más ‘fuertes' de participación. Por lo tanto, el aprendizaje y el ejercicio de formas de control y seguimiento es una cuestión, sino anterior, por lo menos paralela a la toma de decisiones. De todos modos, cabe aclarar que cuando los actores sociales tienen un directo involucramiento en la gestión de sus actividades, la participación se muestra bajo sus diferentes facetas, más allá que estén claramente diferenciadas o no.

También nos interesa el territorio en aquellos aspectos vinculados con el desarrollo cuya perspectiva se inscribe desde un te- 
rritorio, su cultura y su historia (Courlet y Pecqueur, 1994: 81). No vemos al territorio como el 'espacio-lugar' (como soporte de localizaciones materiales y humanas) sí como una conjugación de variadas realidades. Es al mismo tiempo la expresión del 'lugar' específico donde vive y trabaja la población; el ámbito en que se localizan los procesos de concentración y polarización creciente, y que se traduce en marginación social y expulsión del aparato productivo; el espacio que condiciona el destino de la mayor parte de la población de menores recursos; el sitio donde se materializa el accionar de estos actores que nos ocupan; donde se da el primer eslabón -y a veces el único- en la 'potencial' cadena de participación de amplias mayorías sociales; donde se concretan las interacciones, conflictivas o no, entre actores y organizaciones sociales; donde la población trabaja y vive, y donde inicia su camino dirigido a viabilizar y generar acciones y actividades de transformación social, económica, política e institucional.

Según Boscherini y Poma esta perspectiva territorial consiste en otra forma de consideración y tratamiento de los agentes territoriales (actores y organizaciones). En la nueva concepción territorial éstos pasan:

[...] de ser herramientas de government del territorio a agentes de la governance territorial [...] los agentes territoriales dejan de ser 'externalidades' para convertirse en 'agentes' directos de la producción (Boscherini y Poma, 2000: 25).

Y es a través de la modalidad de sus acciones como se abren posibilidades para promover el 'desarrollo' del territorio respectivo, junto con mejores condiciones de vida de sus habitantes. Y esto es lo que aquí consideramos desarrollo local, un 'desarrollo territorial', del ámbito donde la gente vive y trabaja; donde esa gente, esa población está directamente involucrada en la transformación de su realidad y de sus condiciones de vida.

De hecho, la mayor parte de la población sólo desde 'su lugar' podrá tener una proyección hacia lo global. Porque 'su lugar' es el reducto desde el que se fortalece, se capacita y participa para viabilizar sus potencialidades hacia otros escenarios ampliados. Porque la población que nos ocupa es la que está marginada de los procesos de concentración, y por ello sólo se vincula con 'su lugar'. Generalmente conoce lo global (las nuevas tecnologías de la información la han acercado a ese otro mundo) pero no forma parte de sus redes, ni de su lógica. Por esto, 'su lugar' es también el primer eslabón en una potencial cadena de vinculación y de 
participación, que se tornará creciente en la construcción de un futuro diferente.

Cuando estas interacciones (públicas y privadas) se vuelven más frecuentes y regulares, se están dando las condiciones para producir un vuelco transformador y alcanzar un efectivo 'desarrollo local o territorial', más aún cuando involucran al sector pequeño productor, a las pequeñas y medianas empresas. $\mathrm{Y}$ al respecto coincidimos con Poma (2000: 392 y ss.) cuando sostiene que la creación de fuertes interacciones locales es la condición para generar ámbitos espaciales con dinámica y crecimiento productivo y económico, motorizados por el aprendizaje, la capacitación, la innovación, necesarios para ampliar la producción y el mercado local y regional, e incluso alcanzar el mercado global. Esto, definido en otros escenarios como 'atmósfera territorial', es el territorio visto como "eje del tejido productivo" (Boscherini y Poma; 2000: 23) como expresión de la conformación y consolidación de redes de vinculación entre el sector público, la sociedad civil y las empresas (Brett, 1999a: 32 y ss.). Y en estas redes la participación de la población organizada controla y resguarda los intereses de la mayoría de la población y de las pequeñas y medianas empresas, ya que siempre está el riesgo latente de que estos procesos sean absorbidos y dominados por las grandes empresas nacionales y transnacionales.

Sintetizando, las variables centrales que nos ocupan son:

i. El funcionamiento institucional (público y privado) o, dicho de otro modo, el modelo (territorial o local) de aplicación de acuerdos y normas, analizando si opera, o no, con premios, castigos e incentivos dirigidos a impedir la impunidad de transgresiones y delitos;

ii. La participación de los beneficiarios y actores locales en el control y seguimiento del accionar de las organizaciones locales, requisito para garantizar la transparencia, la eficiencia y la solvencia institucional, y

iii. El territorio, como el ámbito de articulación entre agentes territoriales, de promoción del tejido productivo y social, de aprendizaje e innovación. El territorio como la 'atmósfera' con potencialidad transformadora, para mejorar las posibilidades y las condiciones de vida de las mayorías sociales marginales y postergadas. 


\section{Los casos de estudio y la problemática institucional en desarrollo rural}

Nuestras referencias son experiencias puntuales que permiten visualizar las características intrínsecas de modelos institucionales alternativos, vinculados con la participación y el control social en la conformación de un destino común y diferente. A pesar de la crisis, hay realidades territoriales que muestran otro escenario: aquél construido desde el propio hábitat, donde se confunden ambiente y producción, donde la población produce su futuro con mucho esfuerzo, pero con perspectivas (especialmente centradas en mejorar sus condiciones de vida).

En realidad, ejemplos de trabajo solidario centrados en propuestas productivas - no asistencialistas- abundan, especialmente en el medio rural, que es el que aquí nos ocupa. Son modos alternativos de funcionamiento social, de articulación con el Estado y de compromiso de la sociedad civil en la construcción de su futuro. Muchos de ellos, incluso, parten de estrategias instaladas por el propio modelo neoliberal, que se conjugan con la forma de respuesta adoptada por la sociedad; y de este modo enfrentan a la más profunda y prolongada crisis que ha vivido la Argentina en toda su historia.

Alternativas antes inexistentes aparecen en áreas rurales hasta hace poco expulsoras y vaciadas de población. Acciones que facilitan y promueven la vinculación interinstitucional, que se potencian a partir del enfrentamiento de los conflictos interpersonales y sectoriales, que constituyen un aprendizaje para el ejercicio de la gestión y administración institucional. Y que, en definitiva, se constituyen en una opción de trabajo y de vida para afrontar la desesperanza, resultante del cuestionado accionar de la mayor parte de la clase dirigente.

En nuestra investigación nos ocupamos de analizar ciertas realidades territoriales en sus aspectos institucionales; en especial los vinculados con la participación de la población rural, y de pequeñas localidades, en la toma de decisiones y en el control y seguimiento de acciones institucionalizadas. ${ }^{5}$ Tomamos como caso de estudio algunos ejemplos de los muchos existentes en el país. Nos centramos en cuatro casos: dos localizados en la provincia de Jujuy, uno en Salta y uno en Misiones. Y enfocamos: i) en un caso,

S Consideramos acciones institucionalizadas a aquellas que han sido previamente delimitadas y acordadas, en general, a través de convenios formalizados en proyectos o programas. 
en las organizaciones, y ii) en los otros, en el territorio. El primero es una organización de segundo grado - Warmi Sayajsunqo- de apoyo técnico y financiero a comunidades de base (en este caso aborígenes) de Jujuy y Salta, estando la sede localizada en Abra Pampa, Jujuy. Los restantes son experiencias territoriales, a veces asociadas con el desarrollo local. Es el caso de la comunidad de El Tolar (Jujuy) y de las ferias francas (además de las reconocidas ferias de Misiones aquí presentamos la de Aguaray, en Salta, que se origina a partir de aquéllas).

Todos los casos se sustentan en organizaciones de pequeños productores articuladas a otras organizaciones públicas y privadas, y todos persiguen, de distinta forma, mejorar la calidad de vida, a través de diferentes acciones, entre ellas, acceso a la tierra y mejoras en la producción y en la comercialización de sus productos.

\subsection{Warmi Sayajsunqo en la Puna jujeña}

La Asociación de Mujeres Warmi Sayajsunqo (del idioma quechua "Mujer Perseverante") fue creada en 1995 por Rosario Quispe, una campesina de origen kolla que, por su labor con la salud reproductiva de las mujeres aborígenes, recibió numerosos premios nacionales e internacionales. Esta organización de base, de segundo grado, está formada exclusivamente por mujeres andinas (campesinas y kollas) y trabaja en un área extendida: Puna, norte de la Quebrada, parte de la provincia de Salta (en San Antonio de los Cobres y en Santa Victoria).

La asociación está localizada en Abra Pampa ${ }^{6}$ y agrupa, en la actualidad, a 64 comunidades de la Puna y Quebrada (en Jujuy) de Valle Nazareno y Santa Victoria (en Salta) llegando hasta el sur de Potosí (Bolivia). Se ocupa de desarrollar y financiar proyectos comunitarios en artesanías, producción de carne, curtiembre, otorgar microcréditos y generar servicios de desarrollo de negocios, comunicación y capacitación. Y tanto la decisión política, como la ejecución, el control y seguimiento de las acciones es responsa-

${ }^{6}$ Abra Pampa es una pequeña localidad que en 2001 tenía 7,500 habitantes. Se encuentra en el departamento Cochinoca, en la provincia de Jujuy, en la puna argentina, cerca de la frontera con Bolivia, a $216 \mathrm{~km}$ al norte de la capital provincial -San Salvador de Jujuy-, a 1,870 km de la capital nacional, Buenos Aires y a 3,500 msnm. Por su parte, la población de Jujuy equivalía al 1.7\% (611,484 habitantes) de la población nacional (según el INDEC-CNPyv, 2001) y en extensión representa el 2\% del territorio continental argentino. 
bilidad directa de la población vinculada, sea como socia o beneficiaria, a esta organización no gubernamental (ONG).

Rosario Quispe ya era líder al momento de fundar la ONG Warmi. Había sido promotora de diferentes programas de desarrollo (Organización Claretiana de Desarrollo, oclade; Programa Social Agropecuario PSA; Cooperativa Punha de Abra Pampa, PHUNA). En 1997 obtiene el Premio a la «Creatividad de la Mujer en el Medio Rural», otorgado por la Fundación Cumbre Mundial de la Mujer con sede en Ginebra, Suiza y auspiciado por FAO, y en reconocimiento a su trabajo con la salud reproductiva de las mujeres kollas. Muchos otros premios seguirán a éste, y junto a ellos llegará un reconocimiento generalizado y el apoyo de diversas instituciones de promoción y financiamiento, nacionales e internacionales.

A partir de 1997-1998, Warmi comenzó a obtener importantes recursos para aplicar al desarrollo local de parte de la Puna (y de otros ámbitos territoriales cercanos). En la actualidad dispone de una magnitud de fondos que supera a los que aporta para el área el propio estado provincial y nacional. ${ }^{7}$

El más importante, por su magnitud, ha sido el que recibió de Avina, ${ }^{8}$ en marzo de 2001 , por $\$ 800,000$ usD (en dos cuotas) a tres años de ejecución, para un proyecto de Fondos Comunales y otras actividades. Previamente habían obtenido, a fines de 1998, $\$ 10,000$ usD para el diagnóstico participativo y la formulación del Programa de Desarrollo Económico Comunitario, como lo define Avina. Aprobado el programa, recibieron entre 1999 y 2000 , $\$ 150,000$ usD para su ejecución y \$90,000 uSD para capacitación. Paralela y conjuntamente se presentaron a un subsidio de la Inte-

${ }^{7}$ Ha contado con apoyos en recursos de: i) Estado Nacional a través de: Programa Social Agropecuario de la Nación (PSA). Por su alcance territorial -llega a 21 de las 23 provincias argentinas, cubriendo casi todo el territorio argentino- del Fondo Participativo de Inversión Social del Ministerio de Desarrollo Social y Medio Ambiente (FOPAR), Fondo Nacional de las Artes, Fondo de Capitalización Sociedad Anónima, Ministerio de Desarrollo Social y Medio Ambiente (FONCAP); ii) Empresas privadas: Technit, Tec Petrol SA, EDJEDSA; iii) Fundaciones privadas: Navarro Viola, Avina, Sociedad Alemana de Cooperación Técnica, GTZ, Bunge y Born, Mc Donalds, Integrando, IAF, Oftalmológicas Jorge Malbrán.

${ }^{8}$ Avina es una fundación creada en 1994 (de origen suizo) que aporta importantes recursos financieros asociándose con líderes de la sociedad civil y del empresariado en iniciativas vinculadas con el desarrollo sostenible en Iberoamérica. Ha invertido hasta el 2001 y desde sus inicios \$219.5 millones usD. En el mismo lapso en Argentina invertió $\$ 20$ millones USD, de los cuales aproximadamente la mitad corresponden al año 2001 (fuente: http://www.avina.net/web/avina1.nsf/). 
ramerican Foundation (IAF), con lo que consiguieron $\$ 360,000$ USD en 2001 para ejecutar a tres años. ${ }^{9}$

Para alcanzar su propuesta de desarrollo, Warmi realizó un diagnóstico participativo, que significó visitar 50 comunidades desde enero a marzo de 1999. Rosario Quispe llegaba primera para anunciar el carácter de la tarea y convocar a participar; y luego y si estaban de acuerdo, llegaban los técnicos y/o promotoras (cuatro técnicos y ocho promotoras). En cada encuentro comunitario se discutía acerca de la necesidad de recuperar la identidad cultural y el sueño andino (expresado como: "vivir como lo habían hecho los antepasados del propio trabajo y de la producción local").

A raíz del diagnóstico participativo se decidió la constitución legal de la ONG Warmi dirigida a ocuparse de temas de etnodesarrollo. Para ello se diseñó un programa de acción que se subdividió en las áreas de: i) Microfinanzas para la promoción de la actividad productiva y su comercialización; ii) Servicios de Desarrollo de Negocios (centrado en artesanías, curtiembre y carnes ovina y de llama), y iii) Centro de Comunicación y Capacitación para el Desarrollo (producción de videos y otras formas de difusión y capacitación). Las 64 comunidades integrantes de Warmi participan en todos estos componentes y también en otras actividades, algunas tan importantes como la de organizarse para reclamar por el tema de tierras al Estado provincial.

En este tema se abre un campo de acción muy importante, de gran alcance y de consecuencias aún no previsibles, porque ade-

\footnotetext{
${ }^{9}$ A los fines de dimensionar estas magnitudes de asistencia financiera, obsérvese el caso del PSA su antigüedad (comenzó a ejecutarse en abril de 1993), su estrategia y capacidad de acción, es considerado el más importante programa de desarrollo rural. El PSA es financiado con fondos del presupuesto nacional que, en sus mejores momentos (al promediar la década del 90) rondaban los \$10 millones anuales. El PSA ejecutó en toda la provincia de Jujuy hasta el 31 de mayo del 2002 (en nueve años) \$2 millones en crédito dirigido a grupos de productores. (Fuente: http://www.sagpya.mecon.gov.ar/0-8/psa/ resultados\%20alcanzados.htm). Aunque duplicáramos esta cifra para sumarle la asistencia técnica, la capacitación y el funcionamiento operativo, el monto dirigido a toda la provincia de Jujuy por año no superaría los $\$ 500,000$, mientras que la organización Warmi tiene, de una sola fuente de financiamiento y para una zona mucho más pequeña en superficie y población, un monto anual bastante superior (considerando sólo los $\$ 800,000$ usD recibidos en 2001 para tres años). Si agregamos el financiamiento del Programa de Iniciativas en Desarrollo Rural (PROINDER), financiado por el Banco Mundial y el Estado Nacional en $\$ 100$ millones USD, el evidente desequilibro entre fuentes privadas y nacionales continuaría. El PROINDER en tres años, entre 1998 y septiembre de 2001 , ejecutó en la provincia de Jujuy $\$ 427,000$ (en crédito, asistencia técnica y capacitación) a razón de menos de $\$ 150,000$ al año (fuente: http://www.sagpya.mecon.gov.ar/ $0-8 /$ proinder). Todas las cifras puestas en pesos correspondían hasta enero de 2002 (fin de la convertibilidad \$1 USD $=\$ 1$ ) a dólares estadunidenses, y la tasa de cambio es a fines de septiembre de 2002 de $\$ 1$ USD $=\$ 3.65)$.
} 
más de movilizadora es una cuestión conflictiva para la sociedad local. La población aborigen tiene sumo interés por recuperar sus tierras desde que lo habilita la Constitución Nacional de 1994, Artículo 75, Inciso 17.

Warmi ejecuta sus proyectos o actividades mancomunando esfuerzos con otras organizaciones de base, municipios, comisiones municipales, agencias del Estado, aporte de empresas privadas, otras ONG, voluntarias(os) y técnicos comprometidos con la problemática de la Puna.

Los Fondos Comunales se estructuran según la decisión de los beneficiarios, responsables de su diseño, ejecución, control y seguimiento. Su funcionamiento está reglamentado en un Estatuto, discutido y formulado por los referentes de todas las comunidades integrantes de Warmi (tardaron seis meses en formularlo). Los fondos se destinan a microcréditos para la producción de las familias aborígenes. Cada comunidad es responsable de su administración (un tesorero y un Consejo de Crédito, miembros de la comunidad trabajan ad honorem en esta tarea). El primer microcrédito se otorgó en agosto de 2000. Hasta mediados de 2002 se habían entregado 670, habiendo muchas familias que pagaron totalmente, tres morosos y ningún incobrable. Asimismo, el control de estas actividades está programado formalmente (con asambleas generales y delegación en los líderes).

Como vemos, es una organización con directa participación de los beneficiarios (de microcréditos, emprendimientos) en las decisiones y en el control de sus actividades. Los propios referentes de las comunidades fijan la política y la forma de administrar sus recursos. Y, aunque cuentan con el asesoramiento técnico de dos ONG, aparentemente, éstas sólo acompañan generando las herramientas y los recursos adecuados a las necesidades de los dirigentes de Warmi. No toman las decisiones, ni fijan la política a seguir. En la administración de los recursos financieros asesoran y son consultados, pero Warmi es la responsable.

Warmi ha desarrollado amplios vínculos con múltiples organizaciones, privadas y públicas, lo cual le ha facilitado y allegado recursos de distinto tipo (monetarios, de trabajo, de prestación mutua, de materiales, de insumos). Warmi ha revitalizado la vida local de las comunidades y de Abra Pampa donde está su sede, y ha movilizado a los políticos y a la población civil y ha favorecido su interrelación. Sin duda, ha instalado un proceso de capacitación, organización y formación de líderes. Se trata de una expe- 
riencia, si bien aún muy reciente, en principio muy rica para el análisis que nos ocupa.

\subsection{El caso de la comunidad de El Tolar}

El Tolar, también en la Puna, Jujuy, es una comunidad nueva, formada entre 1995 y 1996. Es un caso para analizar formas de repoblamiento rural, de migración de retorno, producto de la vuelta a 'su tierra' de la población que se ha visto afectada por la recesión y la desocupación creciente en diferentes áreas del país. El Tolar es producto del entusiasmo y el esfuerzo de jóvenes aborígenes migrantes que vuelven a su tierra de origen, el hábitat puneño, provenientes de zonas agroindustriales de la provincia de Jujuy.

Esta comunidad se localiza a $35 \mathrm{~km}$ de Abra Pampa, por la ruta 9 que se dirige a La Quiaca. Allí se creó un pequeño poblado, conformado por una población con intereses mancomunados. En ese mismo lugar antes sólo había un caserío diseminado y en franca extinción. Es relevante, asimismo, por el accionar social y productivo de su población, especialmente por su capacidad para afrontar y superar conflictos vinculados con manejos clientelísticos de los recursos disponibles. Por esto interesa conocer su praxis de organización y capacitación, los modelos de participación y los procesos contradictorios de conformación de liderazgo, así como las formas de gestión de sus actividades productivas y obras comunitarias.

Los jóvenes (menos de 10) que conformaron El Tolar habían migrado de su tierra cuando tenían alrededor de 16 años para hacer changas en la producción de tabaco (en Perico, Jujuy) de tomate (en San Juan y Mendoza) o de caña de azúcar (Salta). Al promediar la primera mitad de la década de los años 90 regresan a su hábitat. Allí, para entonces, apenas había dos o tres casas ocupadas por muy pocos habitantes, muchos de ellos ancianos.

Los jóvenes explican su retorno diciendo que comenzaron a percibir que trabajar directamente su tierra les abría mayores posibilidades que continuar como peones rurales o changarines, en condiciones laborales de creciente precariedad. Por ello decidieron conformar una organización local para mejorar sus condiciones de vida y recuperar las costumbres locales y así consolidaron un caserío rural donde actualmente viven 30 familias. Esta comunidad participa de la ONG Warmi, pero también está (o ha estado) asistida por otros programas, como el PSA, el Instituto Nacional 
de Tecnología Agropecuaria (INTA), o la ONG Asociación para la Promoción Integral (API).

Con mucho trabajo y acciones solidarias (no sin conflictos, algunos agudos que han llevado hasta la expulsión de un asociado) mejoraron su calidad de vida y su alimentación. Construyeron nuevas viviendas, invernaderos, huertas, horno solar, curtiembre en cuero; y se dedicaron a la producción de ovinos, bovinos, camélidos y gallinas. Estos animales son de propiedad individual, aunque también tienen ovejas comunes que utilizan cuando necesitan recursos para inversiones comunitarias. Muchos aprendieron nuevos oficios que aplican para beneficio del conjunto (como sanidad animal).

Están en un permanente proceso de capacitación, incluso en actividades complementarias a la rural (música, escritura a máquina y computación); y uno de ellos terminó la escuela secundaria con el apoyo de los demás (sus compañeros lo 'becaron' para que pudiera vivir en La Quiaca mientras estudiaba). Al terminar sus estudios retornó a la comunidad, siendo actualmente el Secretario de la misma.

En esta comunidad, avanzada su primera etapa de organización, surgieron problemas entre sus integrantes vinculados a manejos poco claros de los recursos del conjunto. A poco de empezar a organizarse, se conformaron dos grupos del PSA y en uno de ellos comenzó a haber problemas en su operación; la gestión era autoritaria y poco participativa, se actuaba con métodos clientelísticos. Ello condujo a divisiones entre los miembros, los que rechazaban este proceder y quienes lo apañaban. Eran notorias las diferencias entre uno y otro grupo en el modo de participar, de compromiso y de responsabilidad con las actividades respectivas. En uno, siempre estaban presentes todos, con familiares incluidos y funcionaban con mucha participación, entusiasmo, solidaridad y democracia interna. En cambio, en el otro, no se daba esta dinámica, predominaban las ausencias, incluso algunos miembros del grupo trabajaban en otras comunidades, y hasta se fueron a vivir a otro lugar. La situación se tornó más conflictiva cuando uno de ellos comenzó a operar como puntero político ${ }^{10}$ y a conseguir "Planes Trabajar" para los miembros de El Tolar, pero incluyén-

${ }^{10}$ Termino acuñado que significa que actúa en representación de los intereses de un político o partido y promueve actividades de clientelistas (cambio de favores por votos). Se ocupaba de los trámites de personerías jurídicas para las organizaciones comunitarias (necesarias para reclamar por el derecho a la tierra) y, también, conseguía y repartía 'Planes Trabajar'. 
dose él mismo como uno más de los desocupados de la comunidad con derecho a ser subsidiado, aunque no vivía, ni trabajaba allí. Y parte de la comunidad aceptaba esta trasgresión.

Los problemas en esta comunidad fueron muchos y variados (hubo recursos que desaparecieron). Cambiaron más de una vez de presidente. Tuvieron más de un dirigente que no residía en la comunidad. Hasta que finalmente en el 2000 lograron colocar un dirigente nuevo, residente de El Tolar y la comunidad dio un vuelco de crecimiento.

Han conseguido un fondo comunal (microcréditos) a través de Warmi. En 1999 construyeron ocho invernaderos con fondos del PSA. Recibieron asistencia de Pro Huerta. Consiguieron un horno solar para la producción de electricidad y dispondrán de un boyero eléctrico para el control y cuidado del ganado ovino. Armaron una oficina (donde colocaron la computadora recuperada y arreglada) y se dividieron roles (uno encargado de sanidad animal, otro del botiquín). Ninguno de estos jóvenes tenía nivel secundario, pero valoran la educación. Uno está aprendiendo a escribir a máquina y varios comenzaron a usar la computadora. Incluso algunos manejan el correo electrónico cuando salen de su comunidad.

Asimismo, avanzaron en actividades culturales y de esparcimiento. Construyeron un parque de diversiones para los niños con material de la zona y una sala infantil con ayuda de OCLADE. Hicieron un concurso interno para crear una bandera que identificara a la comunidad. Todos los jóvenes aprendieron a tocar "zica" a partir de las enseñanzas de unos profesores de música de la Universidad de Buenos Aires (UBA). Cada año, desde 1999, realizan el encuentro Intercultural de Comunidades Aborígenes durante un día de septiembre. Invitan a todas las comunidades de la zona a compartir un espacio de revalorización cultural (en 2001, participaron 11 comunidades).

El Tolar es una comunidad muy pequeña en número de población beneficiaria, pero es ámbito de acción de numerosas ONG (API, OCLADE, Warmi, Cedro) y del propio Estado nacional (PSA, UBA, Ministerio de Trabajo y Seguridad Social, investigadores del CONICET aportando estudios de ectoparásitos) y provincial (Universidad Nacional de Jujuy, Instituto de Biología de la Altura). Ello también es parte de la explicación de la dinámica conseguida por un grupo tan pequeño de pobladores originales.

Además de las enseñanzas que aporta este caso, en cuanto al rol de las reglas de juego claras y consensuadas para la superación 
de los conflictos, es una experiencia representativa, en el contexto de desempleo de los grandes centros urbanos, de las posibilidades potenciales que ofrecen zonas que antes eran expulsoras de población. El surgimiento y consolidación de esta comunidad tiene que ver con nuevas oportunidades existentes en la Puna, como es para la población aborigen la recuperación de su tierra. También se vincula con la posibilidad de acceder más fácilmente a algún tipo de ingreso o consumo (por razones de parentesco) o a determinados planes sociales (por razones regionales o étnicas).

\subsection{Las ferias francas}

Las ferias francas son agrupaciones de pequeños productores agropecuarios para comercializar directamente sus excedentes productivos. Constituyen un modelo novedoso y en franco crecimiento de organización comercial articulado con el mercado, que ha impactado considerablemente en la dinámica de desarrollo económico y social de muchas localidades del interior argentino (especialmente de la provincia de Misiones, ${ }^{11}$ pero también en Corrientes y recientemente en Salta, -Aguaray- y Chaco) y en los ingresos y calidad de vida de las familias involucradas. Las ferias son una alternativa para la difusión, colocación y venta en el mercado de la producción de los pequeños productores rurales, para los que generalmente el eslabón comercial constituye el nudo gordiano de su circuito productivo. Y en este sentido, su modelo de funcionamiento, sus reglas de juego, merecen investigarse.

En las ferias francas, los pequeños productores agropecuarios comercializan directamente sus productos o excedentes -que deben ser orgánicos- juntándose una o dos veces por semana en la aglomeración o localidad más cercana a su área de explotación. Para ello, se organizan y formulan su estatuto de funcionamiento, acuerdan cuestiones básicas vinculadas con la producción, la elaboración -controles bromatológicos-, la presentación, los precios. Y acondicionan un espacio físico con los puestos de venta.

\footnotetext{
${ }^{11}$ Misiones está localizada en el noreste argentino y tiene más del $80 \%$ de sus límites internacionales con Brasil y Paraguay. En sus escasos 29,800 km2 (0.8\% del total nacional) tiene $70 \%$ de su superficie en pendiente, por lo cual no es apta para la agricultura, pero sí para la forestación. En el 2001 tenía 961,274 habitantes, 2.7\% de la población nacional (INDEC-CNPyv, 2001).
} 


\subsubsection{Las ferias misioneras}

En la provincia de Misiones, los feriantes tienen parcelas de 20 hectáreas en promedio. Algunos son ex productores de tabaco y yerba mate, cultivos que fueron abandonando por dificultades en la venta, en los precios, o por los problemas emergentes con la toxicidad en el manejo de estas plantaciones. Y, entonces, decidieron comenzar a vender sus productos o excedentes agropecuarios sumándole algún valor agregado (ejemplo: jugos y licores de frutas nativas y silvestres, dulces y mermeladas, granola, quesos de búfala, gran variedad de hortalizas, yerbas medicinales y aromáticas).

Muchas localidades provinciales tienen feria, y algunas más de una. La feria más concurrida es la de la capital provincial, Posadas, que convoca entre dos mil y cinco mil personas cada jornada en sus 70 puestos (que suman unos 150 pequeños productores).

Este modelo de comercialización comenzó en Oberá en agosto de 1995. Un grupo de pequeños productores -apoyados por el Movimiento Agrario Misiones (MAM), por programas nacionales (PSA, Pro Huerta) y por el Ministerio del Agro y la Producción de Misiones- decidieron visitar una feria franca en el sur de Brasil en su búsqueda de alternativas ante la crisis, la falta de ventas y la escasa rentabilidad de sus producciones tradicionales (tabaco, yerba mate). A la vuelta de ese viaje resolvieron comenzar con su propia experiencia en Oberá. La feria franca de Oberá rápidamente se constituyó en un éxito que logró difusión en todo Misiones. Dan cuenta de ello: 45 ferias con unas tres mil familias involucradas siete años después, y la creación de la Asociación de Ferias Francas de Misiones. También, hace tiempo que esta experiencia alcanzó reconocimiento nacional (véase Diario La Nación, 2 de octubre de 2000) replicándose en otras provincias.

En junio de 2002 se realizó un Encuentro Nacional de Feriantes en Paso de la Patria (Corrientes), donde estuvieron presentes representantes de ocho provincias (San Juan, Misiones, Corrientes, Santa Fe, Salta -Aguaray-, Entre Ríos, Chaco y Catamarca Andalgalá-). En Corrientes existen 23 ferias en distintos departamentos apoyadas por el PSA y se ha creado la Comisión Inter Ferias Francas de Corrientes. Y en Salta desde abril de 2000 existe la Feria Franca de Aguaray, de la que nos ocuparemos más adelante.

La mayoría de las ferias tienen una organización formal, con personería jurídica, y están buscando que todas la tengan para poder conformar una organización nacional de ferias francas. 
Además, la personería jurídica habilita a trabajar con factura legal, así como presentarse a proyectos y solicitar financiamientos alternativos.

Diferentes referentes públicos y políticos trataron de captar los beneficios de este pujante emprendimiento. Muchos gobiernos municipales promovieron y colaboraron en su surgimiento y reglamentación, incluso por iniciativa propia. El gobierno provincial creó en el año 2000 una dirección especial vinculada a esta experiencia (Dirección General de Pequeños Agricultores, Huertas y Ferias Francas) dependiente de la Subsecretaría de Reconversión y Diversificación del Ministerio del Agro y la Producción.

Según Nardi y Pereira, la feria de Oberá:

[...] es una de las más grandes de la provincia, ya que está constituida por unos 100 feriantes, que se dan cita dos veces por semana en tres puntos diferentes de la ciudad para ofrecer sus productos [...] En cada localidad las mismas contaron con el apoyo de las organizaciones allí existentes: por ejemplo, en la feria de San Vicente la capacitación y el asesoramiento estuvo a cargo del INTA, del Pro Huerta y del PSA; en feria de San Pedro colaboraron técnicos de la Pastoral Social, del INDES, del PSA y acompañaron las mujeres del grupo Unión y Progreso de Colonia Paraíso; en la feria de Alem la municipalidad ha jugado un papel fundamental desde el origen de la misma [...] el caso de las ferias francas en Misiones es una experiencia que aporta señales e indicadores dignos de tener en cuenta en un análisis institucional y territorial. Se trata de ámbitos locales donde existen formas de gestión que priorizan la promoción de la participación, organización y capacitación de los actores participantes y beneficiarios [y] [...] la generación de una dinámica territorial particular que favorece y potencia nuevas acciones para un desarrollo local autogestionado (Nardo y Pereira, 2002).

\subsubsection{La feria franca de Aguaray, Salta}

La feria de Aguaray ${ }^{12}$ fue creada luego de visitar y reconocer la experiencia en Misiones. Aguaray fue (junto con Tartagal) un epicentro en el norte salteño de la empresa petrolera nacional Yacimientos Petrolíferos Fiscales (YPF) luego privatizada. Esta privatización generó cantidad de despidos y conflictos locales. Ahora hay empresas privadas extranjeras, son refinerías operadoras de pozos petroleros (como Refinol, Tecpetrol, Plupetrol, Panamerican Energy). Algunas de estas empresas encaran actividades de

${ }^{12}$ Aguaray tiene 8,055 habitantes (INDEC-CNPyv, 2001) y se localiza en el extremo noreste la provincia de Salta $(1,079,422$ habitantes, $3 \%$ de la población nacional) muy próximo a la frontera con Bolivia. 
asistencia social (en general, donaciones según demandas de la población necesitada, materiales y bienes para las escuelas, programas de huertas -con abastecimiento de semillas-, instalación de agua y luz).

Los problemas de desocupación que asolan la zona no afectan directamente a la gente de campo, aunque sí indirectamente vía la recesión y la caída generalizada del mercado interno. Más recesiva para este sector fue la liberalización del mercado y el plan de convertibilidad, por la irrupción de mercadería proveniente de la frontera con Bolivia (a poco más de 10 kilómetros de Aguaray). En este contexto de crisis local (y nacional) nace la feria de Aguaray. Primero surgió como iniciativa de los técnicos de la ONG Asociación para el Desarrollo (ADE) y del Proyecto Forestal de Desarrollo (PDF) de la Secretaría de Agricultura, Ganadería, Pesca y Alimentación (SAGPya) movidos por una preocupación de los productores por la comercialización de sus productos. Ellos se preguntaban: “¿para qué mejorar la producción si después no lo podemos vender?” Y los técnicos pensaron en las ferias que conocían de viajes realizados a Misiones entre 1995 y 1996, cuando comenzaron a desarrollarse.

Luego de numerosas tratativas y reuniones entre los feriantes y los técnicos, alcanzaron a formular un reglamento para el funcionamiento conjunto. Ello permitió inaugurar la feria el 15 de abril de 2000 con ocho puestos y unas 10 familias productoras. Dos años después suman 24 familias, con 12 puestos. Funciona los días sábados por la mañana y los feriados en la Plaza de Aguaray.

Es una organización no formal, sin personería jurídica. Los feriantes no pagan tasas y el municipio local los ha asistido con: i) el dictado de la ordenanza municipal que los habilita a funcionar; ii) los mesones y las balanzas (conseguidas en la Aduana); iii) el trámite de la libreta sanitaria; iv) el servicio de bromatología para la carne en pie (un veterinario visita la feria, observa y controla los puestos y otorga el certificado que garantiza calidad); v) el transporte que los traslada con la mercadería, en un recorrido máximo de $15 \mathrm{~km}$, y vi) Un fondo para microcréditos de $\$ 500$ otorgado por la Cooperativa Asistencial del Municipio en abril de 2002.

Todas las ventas son entre minoristas, sin embargo, se han acercado algunos mayoristas. El problema es que carecen de facturas para concretar operaciones, porque no están en su mayoría inscriptos en el monotributo, o bien, porque la feria misma no tiene personería jurídica. 
La feria la componen familias aborígenes y criollas, todos pequeños productores campesinos. No pueden participar familias urbanas (por ejemplo, los artesanos de dulces o pastas caseras). Uno sólo de los integrantes es un ex empleado de YPF despedido con la privatización en 1992 que decidió irse al campo (donde vivía desde los 14 años, pero no producía para la venta) y desde entonces vive de la actividad del campo y de changas (con contratos de uno o dos meses para empresas de construcción que trabajan para las petroleras privadas).

Esta feria ha impactado a la comunidad positivamente y no sólo en lo económico. Es de destacar que ha facilitado el trato entre pobladores urbanos y rurales. Los puestos han evolucionado en diversidad, cambiando el tipo de producto que ofrecen. Cada sábado las ventas oscilan entre $\$ 30$ a $\$ 115$ por puesto (según valores de julio de 2002). Algunos productores tienen una muy diversificada oferta (hay un productor con un predio de 12 hectáreas que suele disponer de 25 productos distintos para vender). Según sostienen informantes y dos productores entrevistados, la situación económica de las familias participantes ha mejorado considerablemente. Además, a partir de la devaluación de enero de 2002, tienen mayores posibilidades de vender por ser zona de frontera, que en este caso particular implica: i) la caída de la competencia de productos especialmente bolivianos; ii) la compra de mercadería nacional por parte de familias bolivianas que cruzan la frontera (del mismo modo que antes los salteños lo hacían en sentido inverso), y iii) la necesidad de sustituir productos manufacturados que ya no pueden ser comprados en la frontera, especialmente Bolivia o Paraguay (se trata de "volver a producir cosas que antes se hacían y ahora no se hacen más, una producción más campesina y artesanal que aquí se perdió”).

La feria, asimismo, fue declarada de interés municipal por la Intendencia y el Consejo Deliberante y lentamente se ha ido integrando a la vida del pueblo, siendo parte de una nueva identidad local, que rompe con formas y concepciones sectarias del pasado. Los feriantes reciben capacitaciones en la Escuela Federal Agrícola (EFA) ${ }^{13}$ de Aguaray. Allí suelen reunirse cada 15 días o cuando hay temas importantes. Y, en general, se llevan muy bien entre ellos.

\footnotetext{
${ }^{13}$ Las Escuela Familiares Agrícolas son instituciones de enseñanza polimodales de alternancia, privada con subsidio estatal. La EFA de Aguaray tiene orientación en ciencias naturales y la alternancia significa un sistema de coeducación con la familia: los alumnos están una parte del tiempo en la escuela y una parte en la casa haciendo tareas similares.
} 
La Feria se constituyó sin ningún apoyo económico, salvo el equipamiento por parte de la municipalidad. Pero ya en el año 2001 consiguieron un subsidio del PROINDER (dos grupos recibieron $\$ 950$ cada uno, para equipamiento para la feria y $\$ 750$ para insumos para la producción). En el 2002 comenzaron a organizar un sistema de microcréditos a partir de un fondo de $\$ 500$ (alrededor de \$140 usD a julio 2002) que consiguió el Intendente y otorgó la Cooperadora Asistencial del Municipio. Para poner en marcha este sistema reciben asesoramiento y capacitación de ADE y dos feriantes van a ser los responsables de administrar el fondo. Se tratará de alrededor de 20 créditos personales de $\$ 25$ cada uno, con garantía solidaria por grupos de feriantes. El crédito se devolverá con los ingresos de cada sábado en 10 cuotas (más dos cuotas de interés) y un periodo de gracia de 15 días.

La feria ha contribuido a la autovaloración de la gente del campo a partir de su interrelación con los del pueblo, quienes aprendieron a reconocer los valores de la vida rural. Se ha desarrollado un espacio social de relación entre la población del campo y del pueblo, antes inexistente y lleno de preconceptos y desconfianza. De este modo, la lógica previa de la comunidad de Aguaray se está rompiendo, porque ahora en la feria se mezclan criollos y aborígenes, ganaderos con agricultores y artesanos, católicos con evangelistas, gente del pueblo con gente del campo. Es decir, a través de la feria se estaría contribuyendo a una integración cultural con y en la sociedad local.

La feria de Aguaray es producto de muchas historias que se entrecruzan. Pero merece reflexionarse acerca de la presencia latente y significativa del Estado. Porque fue el Estado Nacional, a través de sus programas -Programa Federal de Desarrollo (PFD) y Escuela Federal Agrícola (EFA)- el que financió al personal (técnicos) que asesoró e hizo el seguimiento, aportó el material y los servicios utilizados para este emprendimiento. Y porque es el Estado Provincial, especialmente por intermedio del Municipio de Aguaray, el que colabora con las tramitaciones, con el equipamiento y el transporte.

Además, se operó una transferencia de experiencias y conocimientos (desde las ferias Misioneras) a partir de una voluntad y cultura de asistencia y solidaridad por parte de la mayoría de los participantes (técnicos y feriantes).

Es claro que los feriantes contaron con el apoyo y el asesoramiento de los técnicos (cuya inserción era una ONG -ADE- una escuela privada -EFA- y un programa nacional de desarrollo - 
PFD). Pero no es tan claro, aunque sí decisivo, que todos estos técnicos contaban para sostenerse económicamente con sueldos u honorarios del sector público nacional. Ya que detrás de las instituciones que ellos representaban estaba el Estado aportando los fondos destinados a su sustento. Más aún, los escasos subsidios recibidos también provinieron del Estado. Por ello, no podemos menos que preguntarnos: ¿se podría haber iniciado esta experiencia sin el Estado que, aunque con menos recursos y de cada vez menor disponibilidad, sigue siendo la figura promotora, aunque desdibujada, de muchas actividades de este tipo?

Y finalmente, este caso resulta ser una experiencia de interés para el análisis territorial-institucional porque muestra potencialidad de crecimiento, pues: i) la feria ha impreso una mayor dinámica económica y social a una pequeña localidad como es Aguaray; ${ }^{14}$ ii) se ha generado un proceso de reconocimiento e interacción entre diversas identidades, especialmente a través de la vinculación operada entre los pobladores urbanos y rurales; iii) hay un rol significativo y comprometido del sector público nacional y también del municipio local; iv) hay empresas privadas del sector petrolero que encaran actividades sociales de apoyo comunitario para la población local; v) la escuela rural tiene un rol activo en la feria y en la localidad, y vi) la salida de la convertibilidad y la devaluación del peso otorgan a esta área fronteriza posibilidades de crecimiento económico, en el que las ferias podrían cumplir un rol significativo.

\section{Conclusiones}

Detrás de los ejemplos dados hay múltiples instituciones operando, varias con décadas de lucha, con experiencia en la actividad, referentes con historia de trabajo y solidaridad junto a los pobres rurales. Y es de destacar la presencia significativa del Estado en todos los ejemplos. El Estado que estuvo y se mantuvo es aquel que ha podido trabajar al margen de los procesos de degradación pública (porque el sector público tampoco es unívoco).

En realidad, las experiencias expuestas muestran que los modelos de participación y descentralización operan en favor de las mayorías postergadas cuando dejan de ser funcionales a los intereses del poder, cuando se organizan para autogestionar los pro-

${ }^{14}$ El pequeño tamaño de esta localidad, así como su localización muy distante y fronteriza, hacen de ella un caso de interés porque resulta más permeable y aprehensible por la mirada del investigador. 
pios recursos y decidir sobre su uso en forma autónoma y dirigida a la integración productiva, a la inclusión a partir del trabajo y al desarrollo económico sustentable (caso Warmi y Ferias). Cuando, además, hay un Estado que respalda estas actividades (con asistencia económica y técnica) y que se maneja con criterios de necesidad social y no clientelísticos.

Mejor aún sería que ese Estado cumpliera el rol de fijar prioridades, para evitar superposiciones y disputas en los ámbitos regional y local por los recursos. Asimismo, importa su rol en la capacitación de ONG, técnicos y beneficiarios, para viabilizar formas de participación social dirigidas a la eficiencia y efectividad de la autogestión de las organizaciones.

Precisamente, impulsar actividades de articulación institucional (propias del Estado pero no exclusivamente) evita las contradicciones y superposiciones que se generan cuando operan simultáneamente con una misma población diferentes programas del Estado y variadas ONG. Esta necesidad se torna evidente cuando se observan situaciones como: i) ONG que disponen para su accionar de ingentes recursos (varias veces superiores a los del sector público), y cuya disponibilidad y ejecución sin un plan territorial acordado participativa y de forma consensada puede disparar más efectos disruptores que benéficos para el desarrollo local; ii) muchos de los referentes que actúan en las ONG vienen de diferentes experiencias, con posturas ideológico-políticas aparentemente similares, pero con diferentes intereses y perspectivas sobre lo que constituye la participación y la construcción de poder.

Nótese los efectos anárquicos que pueden resultar para un territorio cuando se ve afectado por el accionar desarticulado entre diferentes actores del sector público y del privado. Indagando a referentes de ONG y del Estado que actúan en una misma zona (la Puna jujeña), hemos encontrado tantas estrategias de acción como entrevistados. Por ejemplo, todos perseguían la 'construcción de poder', pero para algunos ello significa fortalecer por abajo las organizaciones de productores y formar líderes fuertes. Para otros, armar un movimiento agrario; para otros formar un partido político para disputarle el poder a los actuales partidos. Estas diferentes estrategias con la misma población no pueden menos que transformarse en una sucesión de marchas y contramarchas en los proyectos y sus respectivas actividades. Si consideramos que se trata de población en situación de riesgo, por déficit alimentario, de salud, educación, etc., los efectos sociales disruptores de una política carente de coordinación son evidentes. 
En síntesis, lo señalado hasta aquí significa revalorizar:

i. El rol del Estado y de los líderes representativos de la sociedad civil como articuladores de intereses sectoriales para organizar y planificar el desarrollo socioeconómico local y regional. Fijar prioridades y minimizar el comportamiento anárquico es una necesidad para el uso eficiente de recursos escasos dentro de un Estado-Nación, una región o una provincia;

ii. El rol del Estado en el financiamiento para el sector pobre, porque es el que ofrece mayor seguridad de regularidad y permanencia en el mediano y largo plazos. Independientemente que en algunos casos puntuales aparezcan -coyunturalmente- organismos o fundaciones financiando montos significativos y superiores a los del Estado;

iii. El cumplimiento de las reglas de juego con comportamientos éticos y transparentes, tanto por parte del sector público como del privado;

iv. El fortalecimiento de las estrategias relacionadas con la capacitación, la autogestión, la autodeterminación y la autonomía de la población marginada (pobres, aborígenes);

v. La cesión organizada-descentralización planificada, no indiscriminada- de funciones, actividades, recursos hacia las ong, identificando experiencia, habilidades, eficiencia;

vi. El control, seguimiento y transparencia de actividades para todas las organizaciones participantes, que las exigencias al respecto se extiendan desde el Estado hasta los beneficiarios, $\mathrm{y}$

vii. Que la apertura y disponibilidad a diferentes formas de control sea también realizada desde y con la participación de la sociedad civil.

Bajo estos condicionamientos, es posible gestar un proceso continuado y creciente de real transformación institucional. Esta alternativa, y en el largo plazo, tiende hacia un nuevo modelo de Estado, con un funcionamiento que sea planificado, coordinado, eficiente y ético. Para ese nuevo modelo hay que tener en cuenta las transformaciones ya operadas en las últimas dos décadas como resultado de la globalización y de las políticas neoliberales, que 
han ido modificando el perfil del Estado. De un Estado centralizado, expresado en la nación, se ha venido pasando hacia un Estado que opera y decide en forma cada vez más transversal -expresado en el creciente rol de los gobiernos provinciales en las decisiones públicas (Oszlak, 2001: 37)- y horizontal-como sucede con el rol de las ONG en la ejecución de funciones-. Es decir, se está modelando una nueva realidad en la forma de hacer política pública, que implica la participación: i) transversal de la nación, las provincias y los municipios, y ii) horizontal del sector público y privado -empresas, organizaciones, cooperativas, ONG, sociedad civil, beneficiarios-. A esta forma es necesario estructurarla para que opere en un contexto de mayor autogestión de la sociedad civil, ejerciendo sus derechos de control y seguimiento para hacer prevalecer la verdad por sobre la impunidad.

\section{Bibliografía}

Ayala Espino, José (1999), Instituciones y Economía. Una introducción al neoinstitucionalismo económico, Fondo de Cultura Económica, México.

Boscherini, F. y L. Poma (2000), "Más allá de los distritos industriales: el nuevo concepto de territorio en el marco de la economía global”, en F. Boscherini y L. Poma (comps.) Territorio, conocimiento y competitividad de las empresas, Miño y Dávila Editores, Buenos Aires, pp. 23-38.

Brett, E. A., (1999a), "Understanding institutions and organisatio$\mathrm{ns}$ " in D. Robinson \& others, Managing development: Understanding inter-organizational relationships, Sage, London.

Brett, E.A. (1999b), Participation and accountability in development management, (mimeo) Development Studies Institute, London School of Economics, London, 23 pp.

Coraggio, José Luis (1998), Economía popular urbana: una nueva perspectiva para el desarrollo local, Instituto del Conurbano, Universidad Nacional de General Sarmiento, San Miguel, Buenos Aires. 
Courlet C. y B. Pecqueur (1994), "Sistemas industriales locales en Francia: un nuevo modelo de desarrollo", en Benko G. y A. Lipietz, Las regiones que ganan, Ediçions Alfons El Magnánim, Valencia, pp. 81-101.

Fundación Avina (2002), "Avina en números" en <http:// www.avina.net/web/avina1.nsf/>, junio del 2003

INDEC-CNPyv (2001), Censo Nacional de Población y Vivienda, Instituto Nacional de Estadística y Censos de Argentina, 2002, Buenos Aires.

INDEC-EPH (2002), Encuesta Permanente de Hogares, Instituto Nacional de Estadística y Censos de Argentina, mayo 2002, Buenos Aires.

Manzanal, Mabel (1995), “Globalización y ajuste en la realidad regional argentina: ¿Reestructuración o difusión de la pobreza?", Realidad Económica 134, IADE, Buenos Aires, pp. 69-82.

Nardi, M.A. y S. Pereira (2002), “Dinámicas territoriales y desarrollo rural en la Argentina: el Programa Social Agropecuario y las Ferias Francas en la provincia de Misiones”, IV Coloquio sobre Transformaciones Territoriales, "Sociedad, Territorio y Sustentabilidad: Perspectivas desde el Desarrollo Regional y Local", Asociación de Universidades Grupo Montevideo-Universidad de la República, 21 a 23 de agosto, Montevideo, Uruguay.

North, Douglass (1999), Institutions, Institutional Change and Economic Perfomance, Cambridge University Press, Cambridge.

Nun, José (2003), "Hay que volver a un nacionalismo sano”, Clarín, Zona, Buenos Aires, 26, enero, 2003, pp. 2-4.

Oszlak, Oscar (2001), “El Estado transversal”, Encrucijadas UBA, Revista de la Universidad de Buenos Aires, Núm. 6, año 1, abril 2001, Buenos Aires, pp. 30-41. 
Poma, Lucio (2000), "La producción de conocimiento. Nuevas dinámicas competitivas para el territorio", en F. Boscherini, y L. Poma (comps.) Territorio, conocimiento y competitividad de las empresas, Miño y Dávila Editores, Buenos Aires, pp. 373-422.

Secretaría de Agricultura, Ganadería y Alimentos (2003), "Programa social agropecuario, resultados alcanzados" en $<$ http://www.sagpya.mecon.gov.ar/0-8/psa/ resultados\%20alcanzados.htm>, junio del 2003.

Secretaría de Agricultura, Ganadería y Alimentos (2003), "Programa de iniciativas en desarrollo rural” en <http:// www.sagpya.mecon.gov.ar/0-8/proinder $>$, junio del 2003.

Enviado: 30 de junio de 2003. Aceptado: 24 de noviembre de 2003. 